\title{
Futurismo científico y distopías en el cuento mexicano del siglo XIX: la ciencia ficción de Amado Nervo en "El sexto sentido" y "La última guerra"'
}

\author{
Scientific Futurism and Dystopia in the Mexican Short Story in the $19^{\text {th }}$ \\ century: Amado Nervo's Science Fiction in "El sexto sentido" and \\ "La última guerra" \\ MARÍA DE LOS ÁNGELES RODRÍGUEZ CASTILLO \\ Universidad de Guadalajara \\ México \\ angeles_rodriguezcastillo@hotmail.com
}

(Recibido: IO-O7-20I7; aceptado: 22-OI-2OI9)

\begin{abstract}
Resumen. El siguiente texto es un análisis de dos cuentos de Amado Nervo, escritor mexicano del siglo XIX. Estos cuentos son "El sexto sentido" y "La última guerra", los cuales son analizados de acuerdo con las características señaladas en la literatura de ciencia ficción, género literario que ha sido poco estudiado en México. Para este análisis, se toma como base principal los rasgos distintivos que Guillem Sánchez y Eduardo Gallego mencionan del género en su ensayo “QQué es la Ciencia-Ficción?". De este modo, se demuestra la incursión del autor en este tipo de literatura.
\end{abstract}

Palabras clave: Análisis literario; ciencia ficción; cuento; literatura latinoamericana.
Abstract. The present paper analyzes two short stories by Amado Nervo, a Mexican writer from $19^{\text {th }}$ century. The short stories, "El sexto sentido" and "La última Guerra," are studied following the characteristics mentioned in science fiction literature, a little studied genre in Mexico. The main pillar for this study are the distinctive features Guillem Sánchez and Eduardo Gallego mention about the genre in their essay "What is science fiction?" In this way, the incursion of this author in this type of literature is proved in this paper.

Keywords: Literary analysis; science fiction; short story; Latin American literature.

\footnotetext{
${ }^{\text {I }}$ Para citar este artículo: Rodríguez Castillo, M.A. (2OI9). Futurismo científico y distopías en el cuento mexicano del siglo XIX: la ciencia ficción de Amado Nervo en "El sexto sentido"y "La última guerra". Alabe 2o. [www.revistaalabe.com]

DOI: I0.I5645/Alabe20I9.20.2
} 
La ciencia ficción mexicana se enfrenta a un amplio muro que no ha permitido el estudio exhaustivo que merece: el desconocimiento y poca divulgación de su producción, que es tanto basta como de alta calidad. El lector suele relacionar este género con autores europeos o estadounidenses, ya sea el padre de la ciencia ficción, Julio Verne, o el americano Ray Bradbury, entre otros escritores de gran renombre.

Respecto a ello, el investigador del tema Miguel Ángel Fernández (20I3) comenta:

Hasta hace unos diez años, todavía se escuchaba a ciertos autores o investigadores que aseguraban que la ciencia ficción nunca había existido en este país; o que era tan poca y tan mala, que no valía la pena molestarse en leerla; o bien, que ellos habían dado inicio al género en México. Aunque existía la tesis doctoral de Ross Larson, publicada en forma de libro en I977, con un capítulo sobre el tema -ignorada hasta 1997-, el principal obstáculo para estudiar la ciencia ficción mexicana ha sido siempre un problema de clasificación, ya que hasta la fecha los editores consideran un mal augurio publicar cualquier cosa bajo la etiqueta de "ciencia ficción”2

Sin embargo, la literatura de este tipo en el país tiene un camino fructífero que se inicia en el siglo XVIII de la mano del fraile Manuel Antonio de Rivas, que en I775 (Bernardo Fernández, 20IO) imagina un viaje a la Luna en un carro volador, relato que lo llevó a rendir cuentas frente al tribunal del Santo Oficio. Tiempo después la producción continuó y tomó fuerza con autores del siglo XIX.

Trabajos de investigación recientes colocan a Amado Nervo (I87O-I9I9) como uno de los precursores de la ciencia ficción en México (Fernández I3), sin embargo, la historia literaria resalta del escritor únicamente incursión en el modernismo, y cómo el papel del autor en este movimiento dio un gran impulso al género fantástico.

Respecto a las características de la prosa modernista cabe resaltar el decadentismo, no porque se encuentre en un primer nivel de la anécdota principal de la prosa de Nervo, sino porque en su narrativa se hallan discursos laterales (Martínez 20Io) en los que se detecta el hartazgo o actitud reaccionaria al progreso de la modernidad, rasgo que destaca Gerard Vilar en la corriente decadentista (Corral p. 235), que se manifiesta en el recelo de fin de un siglo y albores de uno nuevo donde la ciencia y la razón no han satisfecho los misterios que rodean al hombre, escepticismo que se transforma muchas veces en una "visión irónica de la vida” (K. Poe citada en Bermúdez 2OI3).

\footnotetext{
${ }^{2}$ Se trata de un documento en línea. Fernández, Miguel. (20I3). "Panorama de la Ciencia Ficción mexicana”. En Ciencia Ficción mexicana. Consultado el 8 de junio de $2 \mathrm{OI}$ desde http://cfm.mx/?cve= II:26
} 
Este “otro Nervo”, como lo llama Manuel Durán (2008), que se halla en su prosa, es reaccionario a ese progreso que lo circunda, contexto positivista, de darwinismo social, en el que solamente "los fuertes, los ricos, los listos, tienen derecho a la vida y al futuro" (Durán p XVII). Esta decepción a la fe en la ciencia de su época permanece en los relatos de ciencia ficción que el modernista escribe.

Es común que la narrativa de este escritor sea solamente relacionada con el género fantástico por los críticos, como para Emanuel Carballo (I99I), quien hace hincapié que en la prosa este autor lleva al cuento modernista al terreno de lo sobrenatural, y no menciona su visión futurista. De la misma forma lo señala Carlos González Peña (2OI2), al indicar únicamente la fantasía de sus narraciones, señalando de forma especial el $D_{o \text { - }}$ nador de Almas y "El ángel caído", así como la constancia en el cultivo de dicho género. Ante esta omisión y para lograr enmarcar a Nervo dentro de la ciencia ficción, es necesario marcar la comparación entre este género y lo fantástico, y mostrar algunas propuestas de definición acerca del primero.

La razón de esta categorización o generalización de su obra puede deberse en gran parte, de acuerdo con Max Miler (citado en Herrero, 2000), a que los límites entre estos dos tipos de literatura, la ciencia ficción y el género fantástico, aún no han sido demasiado marcados, ya que el pensamiento científico no está libre de motivaciones que pueden resultar irracionales. Otra de las causas por las que Nervo no ha sido abordado lo suficiente desde esta perspectiva es que los géneros mencionados son periféricos en relación con el realismo; la mayoría de los historiadores y críticos de la literatura mexicana apenas tocan el desenvolvimiento de lo fantástico, y no se atreven a asomarse siquiera al de la ciencia ficción.

Aunque ambos géneros, lo fantástico y la ciencia ficción, no se atienen a las leyes conocidas que rigen la naturaleza en la contemporaneidad del autor, la diferencia entre estos radica en que la primera juega con las potencialidades de la razón y extrapola los poderes de esta, mientras lo fantástico introduce un mundo irracional (Herrero, 2000), no solo las motivaciones, como en el caso del género también conocido en español con las siglas CF. Esto quiere decir que mientras lo fantástico rompe las leyes de la realidad, la ciencia ficción las extiende, hace que cosas impensables quepan dentro de una realidad posible del ser humano.

Isaac Asimov suma a la discusión acerca de la diferenciación de estos géneros, clasificados para él como ficciones surrealistas. En el libro Apuntes sobre ciencia ficción (20I5), declara a lo fantástico como una literatura cuyos ambientes expuestos no pueden derivarse de la acción humana, mientras que en la ciencia ficción, la historia podría derivarse de "nuestro propio medio" a través de la transformación en los ámbitos científico y tecnológico, que no siempre se relacionan con el progreso:

(...) El cambio podría representar un avance, como el desarrollo de colonias en Marte, o la interpretación de señales provenientes de formas de vida extraterrestre. Podría representar un retroceso, como en una descripción de la destrucción 
de nuestra civilización tecnológica por una catástrofe nuclear o ecológica. Con una estimación generosa de los avances científicos que podemos lograr, sería posible incluir ciertos ítems menos verosímiles como el viaje en el tiempo, las velocidades superiores a la de la luz, etcétera. (Asimov, 20I5, p 9-IO)

El escritor considera que la ciencia ficción depende del concepto de cambio social y que antes de que el asumo de éste existiera, hubiera sido imposible el inicio del género, por ello resalta la importancia de la revolución industrial para el desar rollo o evolución de esta clase de literatura. Se puede inferir de la posición de Asimov que lo crucial no es una predicción de un cambio particular, sino la acción de considerar la transformación como parte de la acción voluntaria del hombre en la sociedad. Estos motivos conforman su definición acerca del género, basada en el vínculo que el hombre guarda con los avances. Según sus propias palabras:

Por primera vez, alguna gente llegó a entender que no solamente el cambio ocurría, sino que seguiría ocurriendo después de su muerte. Esto significaba que ocurrirían cambios mayores que los que una persona hubiera podido haber visto en su vida, cambios que ella nunca vería. (...) La respuesta literaria a esa nueva curiosidad fue lo que ahora llamamos "ciencia ficción”. (...) La ciencia ficción puede ser definida como aquella rama de la literatura que trata sobre las reacciones de los seres humanos a los cambios en la ciencia y la tecnología. (Asimov 20I5, p 40)

Otras propuestas de definición o caracterización del género que resultan útiles son las hechas por Fernando Ángel Moreno y Lola López Martín. En su ensayo "La ficción prospectiva: propuesta para una delimitación del género de la ciencia ficción”, Moreno considera a la ciencia como una temática, pero no como esencia de la anécdota, pues "la humanidad" continúa siendo el punto central en la ciencia ficción (Moreno, 2008, p 65). Aunque no deja de señalar la importancia y frecuencia de este contenido, así como el tema de visión a futuro, el autor enfatiza que la mayor parte de la "buena" ciencia ficción aborda asuntos filosóficos o "al menos profundiza en cuestiones fundamentales de la cultura humana” (Moreno, 2008, p 66).

Su planteamiento está basado en un pensamiento positivista, que entiende a la realidad como independiente de la subjetividad humana. "Lo que se problematiza es la lectura que hacemos de la realidad y todo lo que hemos construido a partir de dicha lectura” (Moreno, 2008, p. 77). Según el mismo autor, hay un pacto de ficción que se sostiene en la tensión que existe entre la sensación de lo conocido y la del no reconocimiento.

(...) El lector cree todo el rato reconocerse, pero también ve continuamente que eso no es así. El resultado de esa tensión es que el lector se pregunta por qué no es así. El fantástico dice: «No puede ser, pero es». La ciencia ficción dice: «En el campo referencial interno es, pero en el campo referencial externo podría 
haber sido». Y si podría haber sido, y creo de verdad que podría haber sido así... Entonces ¿quién soy yo? ¿Cuánto forma parte de la sociedad y cuánto de las posibilidades de la realidad? Ni yo ni mi mundo somos lo que pensaba. Ha cambiado entonces mi lectura de la realidad. (Moreno, 2008, p 78)

Su postura respecto al género podría definirse así: la ciencia ficción es la literatura que exige cláusulas que se derivan de la realidad existente y de lo que el humano es o podría ser (Moreno, 2008, p. 79).

En su tesis doctoral, titulada Formación y desarrollo del cuento fantástico hispanoamericano en el siglo XIX, Lola López Martín brinda un espacio para exponer rasgos de la ciencia ficción. Recoge el consenso de la crítica moderna que señala como característica de la ciencia ficción el intento por la recuperación de "la fascinación en el milagro, en una sociedad desacralizada, pero sin la intervención de Dios, ni del diablo, sino a través de un individuo o héroe autónomo que aspira a la omnipotencia a través de la ciencia que sustituiría al nigromante" (López, 2009, p.I83).

La autora retoma los motivos de la ciencia y tecnología para describir al género, que introduce "el idealismo" de los avances de los campos mencionados en un ambiente conocido como la realidad del lector. Por esta razón, este tipo de literatura apuntará a explotar los efectos extremos “del poder de la razón y de la ciencia”. (López, 20o9, p.I83). Es, al igual que lo fantástico, una manera de exponer e intentar dar una contestación a las inquietudes de la sociedad, en esto encontramos una coincidencia con Fernando Ángel Moreno respecto a la preocupación acerca de las problemáticas humanas:

(...) el fantástico y la ciencia ficción se constituyen a lo largo del siglo XIX como respuestas estéticas a los interrogantes que siguen preocupando al hombre en su ansiada fusión de lo racional demostrable y lo sentimental intuitivo. (López, 2009, p. 184)

Si atendemos a las características revisadas, las narraciones "El sexto sentido" y "La última guerra" del escritor mexicano Amado Nervo pertenecen a la ciencia ficción, pues ambas obras se centran en las potencialidades que el ser humano tiene a través de sus herramientas básicas para el cambio: la ciencia y la tecnología, o bien, derivan del "propio medio" de la humanidad que ha transformado su modo de vida y enfrenta las consecuencias en el futuro, transformación que en el cuento "La última guerra" se encuentra lejos de representar un avance o beneficio para el hombre. Los dos cuentos abordan además un problema humano sin detenerse en explicaciones sobre el avance de la ciencia o la evolución de la sociedad.

"El sexto sentido" es un relato dividido en seis secciones en la que un narrador protagonista cuenta acerca de una operación cerebral experimental a la que es sometido, y que le permite ver su futuro como si se tratara de una colección de imágenes sucesivas. 
Los sucesos futuros, las personas en juego con ellos, las cosas a ellos relativas, el escenario en que debían realizarse, todo estaba delante de mí en perspectiva admirable, y la sucesión de los hechos diversos se me revelaba por la reproducción del mismo hecho, con las variantes y las progresiones necesarias. (...) Veía yo el futuro como se ven las tiras de papel de kinetoscopio. Supongamos que se tratase de la caída de un hombre desde un balcón. Primero veía al hombre en el momento de desprenderse, luego desprendido, después agitándose en el aire, en seguida estrellándose en la arena (...)

En cuanto a mí, me contemplaba en todos actos futuros y sucesivos de mi vida, era aquella una muchedumbre inmensa de yos (...) (Nervo, I99I, pp. 36o-37I).

En sus visiones, el hombre conoce a quien se convertirá en el amor de su vida y la forma en la que se separarán. En este cuento, Nervo trae a colación un poder sobrehumano, como es el ver el futuro. Este don que llega a tener el protagonista no sucede por causa de la magia, sino por una acción en la que la ciencia médica interviene, esto es una operación. Aun así, el elemento más allá de lo natural conocido se encuentra aquí, ya que ese poder no está presente en el mundo real.

El otro cuento de Nervo que ejemplifica su cultivo de la ciencia ficción es "La última guerra". En este mundo futuro que Nervo narra, los animales dominan ya un idioma y se han rebelado contra los humanos.

Los hombres, a pesar de su astucia, fuimos sorprendidos en todos los ámbitos del orbe, y el movimiento de los agresores tuvo un carácter tan unánime, tan certero, tan hábil, tan formidable, que no hubo en ningún espíritu siquiera la posibilidad de prevenirlo...

Los animales manejaban las máquinas de todos géneros que proveían a las necesidades de los elegidos; la química era para ellos eminentemente familiar, pues que a diario utilizaban sus secretos: ellos poseían además y vigilaban todos los almacenes de provisiones, ellos dirigían y utilizaban todos los vehículos... Imagínese, por tanto, lo que debió ser aquella pugna, que se libró en la tierra, en el mar y en el aire... La humanidad estuvo a punto de perecer por completo; su fin absoluto llegó a creerse seguro (seguro lo creemos aún) ... y a la hora en que yo, uno de los pocos hombres que quedan en el mundo, pienso ante el fonotelerradiógrafo estas líneas, que no sé si concluiré, este relato incoherente que quizá mañana constituirá un utilísimo pedazo de historia... (Nervo, I99I, pp 244-245).

El modernista cuenta acontecimientos que se basan en una visión futurista, milenios y milenios después de la era en la que hoy vive el ser humano. En el texto, la fecha que se señala es "3, 502 de la nueva era, (o sea 5, 532 de la Era Cristiana)". El tema de los animales que infringen las normas naturales (tal es el caso del habla y del raciocinio como se plantea en el relato) fue también utilizado por otro autor decimonónico como es 
Vicente Riva Palacio en su cuento "El buen ejemplo". Cabe señalar además que el texto de Nervo fue escrito antes que La rebelión en la granja (1945) de George Orwell, en el que también hay un levantamiento de los animales contra el ser humano.

De acuerdo con Guillem Sánchez y Eduardo Gallego, la ciencia ficción es una literatura especulativa que se fundamenta en explorar "una idea o situación prodigiosa" que determina el nudo narrativo (2). Esta idea se circunscribe a un tema dentro del género. Los autores logran una clasificación de algunos de los temas más comunes de la ciencia ficción, en los que muestran ejemplos y contraejemplos tanto de obras literarias como cinematográficas. Los ejemplos son los siguientes:

\begin{tabular}{|c|c|c|}
\hline \multicolumn{3}{|c|}{ Temas comunes de la ciencia ficción ${ }^{3}$} \\
\hline TEMA & EJEMPLO DE CIENCIA FICCIÓN & CONTRAEJEMPLO \\
\hline Avances en la ciencia & $\begin{array}{l}\text { Un abismo en el cielo de Vernor } \\
\text { Vinge }\end{array}$ & $\begin{array}{l}\text { El origen de las especies de } \\
\text { Chales Darwin }\end{array}$ \\
\hline Utopías y distopías & 1984 de George Orwell & Utopía de Tomás Moro \\
\hline Exploración del espacio & $\begin{array}{l}\text { 2001, Una odisea en el espacio de } \\
\text { Arthur C. Clarke }\end{array}$ & $\begin{array}{l}\text { Cualquier libro de historia } \\
\text { astronáutica, como Alas Rojas } \\
\text { de Manuel Montes }\end{array}$ \\
\hline Aventura & $\begin{array}{l}\text { La Guerra de las Galaxias de Geor- } \\
\text { ge Lucas. }\end{array}$ & $\begin{array}{l}\text { Los tres mosqueteros de Ale- } \\
\text { jandro Dumas }\end{array}$ \\
\hline Policiaco & $\begin{array}{l}\text { Serie de Los príncipes demonio de } \\
\text { Jack Vance }\end{array}$ & $\begin{array}{l}\text { El halcón maltés de Dashiell } \\
\text { Hammett }\end{array}$ \\
\hline Sátira & $\begin{array}{l}\text { Dar de comer al sediento de Eduar- } \\
\text { do Gallego y Guillem Sánchez }\end{array}$ & Sátiras de Juvenal \\
\hline
\end{tabular}

\footnotetext{
${ }^{3}$ Los temas, ejemplos y contraejemplos de la tabla fueron señalados por los autores que se mencionan.
} 
De acuerdo con la clasificación de Sánchez y Gallego, se podría catalogar a los cuentos mencionados de Nervo dentro de los dos primeros temas.

En "El sexto sentido", se explota el tema de avances en la ciencia. A pesar de que la publicación de este texto fue a inicios del siglo XX, Nervo es considerado un autor del siglo XIX por las características de su trabajo, especialmente por su influencia y desarrollo durante el modernismo. Es precisamente la exploración y especulación científica otro rasgo de su formación decimonónica.

(...) La imaginación literaria siempre ha sido deudora de la concepción del mundo propia de su época y es durante el siglo XIX cuando la concepción tradicional sufre un cambio notable: el futuro se hace añicos. (...) El auge de la ciencia durante el siglo XIX demuestra que el futuro puede ser distinto: los cambios pueden derribar su inmutabilidad y la concepción tradicional se agrieta. (Sánchez y Gallego, p. 2)

Hay en esta centuria, de acuerdo con Sánchez y Gallego, una preocupación por lo que la ciencia puede crear, por los alcances que esta puede tener y las consecuencias que estos traerán. En el caso el cuento de Nervo, el avance que se muestra corresponde a la ciencia médica:

- ¿De suerte que usted insinúa la posibilidad de que todos veamos el futuro?

- Ya lo creo; y antes de dos siglos, buena parte de la humanidad, los más afinados, lo verán sin duda... Ahora mismo, dados los adelantos admirables de la histología, un Ramón y Cajal..., yo mismo, vamos, podría acaso dar a un cerebro, mediante operación relativamente sencilla, esa facultad de percatarse del mañana, de conocerlo, de verlo con la misma visión clara y precisa que se ve el ayer... Esto nada tiene, en suma, de extraordinario-siguió el doctor, sonriendo de la expresión de asombro que advertía en mi semblante- ¡Quién sabe si, desplazando ligeramente un lóbulo cerebral, si orientando de diferente modo la circunvolución de Broca, o desviando un haz de nervios, como asienta un perspicaz pensador, se lograría el milagro!... ¿Pero habría hombre que se atreviese a ponerse en nuestras manos para esa operación? (Nervo, I99I, p. 36I).

Nervo no utiliza largas explicaciones acerca de la operación ni de los mecanismos que en esta se aplican, y tampoco es necesario, ya que no pertenece a la ciencia ficción dura, como lo menciona el especialista H. Pascal, la cual se apega a la tecnología y la ciencia por encima de la misma literatura, y solo se enfoca en extrapolaciones para lograr sus fines narrativos. "Amado Nervo es, sobre todo, un jugador, un ser lúdico que reacomoda sus temas y visiones a la intuición que tiene del mundo, del amor, de la inmortalidad, de lo cotidiano y del futuro.” (H. Pascal, 2OI3) ${ }^{4}$. ${ }^{4}$ Se trata de un documento en línea. Pascal, H. (2OI3). “La Maquinaria Lúdica de Amado Nervo”. En Ciencia
Ficción mexicana. Consultado el 5 de junio de 2OI7 desde http://cfm.mx/?cve=II:27 
Sin embargo, esto no excluye al mencionado cuento del género, pues toma la herramienta llamada "ciencia imaginaria". Mientras la ciencia ficción hard, o dura en español, se ciñe al rigor y el uso del conocimiento científico disponible, aquella que usa el instrumento de la ciencia imaginaria crea nuevos ambientes científicos que son verosímiles no de acuerdo con la realidad de la ciencia contemporánea al autor, sino dentro de la realidad de la ciencia del texto:

(...) (ambientes) dominados por la parafernalia científica, las máquinas, laboratorios, (...) todo aquello que, mediante la especulación, los autores logran hacer creíble. Obsérvese empero, que digo creíble, no cierto. A menudo los progresos tecnológicos no son posibles según el estado de conocimiento disponible en ese momento. Entonces el racionalismo especulativo de la ciencia ficción actúa como mera figura literaria: la puesta en escena, el decorado, la jerga tecnocientífica, permiten dar un barniz de veosimilitud al relato, aunque este no se ajuste a las leyes de la ciencia.(Sánchez y Gallego, p. 3)

Nervo habla de la ciencia en "El sexto sentido", pero no de la ciencia disponible en su contemporaneidad, y produce una sensación de asombro sin justificar, solo basándose en una visión futurista de la medicina, de este modo logra la ya mencionada "hipótesis imaginativa”. Para ejemplificar la ciencia imaginaria, Sánchez y Gallego mencionan a H. G. Wells en La máquina del tiempo, y la cinta La Guerra de las galaxias, creada por G. Lucas, entre otras obras.

De vuelta con la clasificación de Sánchez y Gallego acerca de los temas de la CF, podemos encasillar el segundo texto de Nervo, "La última guerra", con el tema de Utopías y distopías. En el texto, se habla de un futuro miles de años después de la centuria en la que fue escrito, la realidad planteada sucede en 3, 5O2 de lo que se llama la Nueva Era. En su futuro se presenta tanto una utopía en la que las clases sociales no existen entre los seres humanos, como una distopía en la que la humanidad ha sido vencida por los animales.

Según Estrella L. Keller, una utopía es un "sueño de perfección social”, que supone confianza en la capacidad humana para alcanzar el ideal; nada está al azar, la justicia está vigente y todos los miembros están satisfechos con su integración en esa sociedad (Keller, I99I, pp. 7-9); mientras que la distopía o utopía negativa se caracteriza por exponer los hipotéticos "desarrollos perniciosos" de la sociedad contemporánea y se representan los temores que se tienen ante la política y la ciencia (Keller, I99I, pp.I5-I6). En el cuento de Nervo, se menciona el paso anterior por un mundo utópico, pero esta sociedad armoniosa contempla como parte de sus miembros únicamente a los humanos y excluye a los animales, que se han convertido en la clase oprimida. Esta relegación traerá resultados desfavorables: inmersos en una distopía, los humanos enfrentarán la respuesta reaccionaria de una política que privilegiaba sólo a ellos. 
Fredric Jameson a lo largo de su libro Arqueologías del futuro: el deseo llamado utopía y otras aproximaciones de ciencia ficción, señala cómo las utopías de la ciencia ficción surgen para expresar ideas políticas relacionadas con el marxismo, y se reflexiona acerca de la desigualdad de clases.

(...) la forma utópica es en sí una meditación representativa sobre la diferencia radical, la otredad radical, y sobre la naturaleza sistemática de la totalidad social, hasta el punto de que uno no puede imaginar ningún cambio fundamental de nuestra existencia social que antes no haya arrojado visiones utópicas cual sendas chispas de un cometa. (Jameson, 2009, p.9).

En el futuro planteado en "La última guerra" se menciona una revolución social, antes de la cual la clase trabajadora, bajo el yugo de los ricos, había sufrido incluso cambios físicos, y el deterioro de salud de los adinerados por las comodidades que tenían y su falta de movimiento:

(...) Cuéntase, en efecto, que antes de la Revolución había, sobre todo en los últimos años que la precedieron, ciertos signos muy visibles que distinguían físicamente a las clases llamadas entonces privilegiadas, de los proletarios, a saber: las manos de los individuos de las primeras, sobre todo de las mujeres, tenían dedos afilados, largos, de una delicadeza superior al pétalo de un jazmín, en tanto que las manos de los proletarios, fuera de su notable aspereza o del espesor exagerado de sus dedos, solían tener seis de estos en la diestra, encontrándose el sexto (un poco rudimentario, a decir verdad, y más bien formado por una callosidad semiarticulada) entre el pulgar y el índice, generalmente. (...) Los gremios de conductores de vehículos y locomóviles de cualquier género, tales como aeroplanos, aeronaves, aerociclos, automóviles, expresos magnéticos, directísimos transetéreolunares, etc., cuya característica en el trabajo era la perpetua inmovilidad de piernas, habían llegado a la atrofia absoluta de éstas, al grado de que, terminadas sus tareas, se dirigían a sus domicilios en pequeños carros eléctricos especiales, usando de ellos para cualquier traslación personal. (...) (Nervo, I99I, p 240 ).

Se señalan avances en la tecnología que llevaron a la decadencia física: "aeroplanos, aeronaves, aerociclos, automóviles, expresos magnéticos, directísimos transetéreolunares, etc.”. Es decir, las actividades de acuerdo con su gremio o clase llevaron a la degeneración de sus cuerpos, así como la transformación de las manos de la clase que laboraba, de este modo el texto sigue la teoría de Darwin acerca de la adaptación de las especies, en el que han surgido cambios para su supervivencia.

Luego llega la utopía a la humanidad, las diferencias de clases se extinguen: 
(...) La Revolución social vino, empero, a cambiar de tal suerte la condición humana, que todas estas características fueron desapareciendo en el transcurso de los siglos, y en el año tres mil quinientos dos de la Nueva Era (o sea cinco mil quinientos treinta y dos de la Era Cristiana) no quedaba ni un vestigio de tal desigualdad dolorosa entre los miembros de la humanidad. (...) (Nervo, I99I, p. 240)

La igualdad entre los humanos que existe en la nueva sociedad ideal planteada por Nervo ha llevado a una paz de siglos, por lo que las armas son prácticamente un vestigio, y se muestran en los museos, ya que las naciones no tienen conflictos entre sí. "El mundo, he dicho, había olvidado ya su historia de dolor y de muerte; sus armamentos se orinecían en los museos, se encontraba en la época luminosa de la serenidad y de la paz (...)". (Nervo, I99I, p. 244)

Dentro de los aspectos a considerar para que un texto sea clasificado dentro del género de ciencia ficción, se encuentra el tiempo. De manera resumida, los críticos coinciden en que, si la historia pasa en el futuro, se está hablando meramente de ciencia ficción, pues se trata de una especulación "ya sea del devenir de la ciencia, de la sociedad o de los personajes" (Sánchez y Gallego, p. 7). En el caso de "La última guerra”, estamos hablando del acaecer de la sociedad, de une evolución de la misma. En este futuro, los animales se emplean para labores del hogar y han desarrollado incluso un lenguaje:

La ignorancia del inmenso complot que se fraguaba en todas partes se explica, por lo demás, perfectamente, por varias razones: en primer lugar, el lenguaje hablado por los animales, lenguaje primitivo, pero pintoresco y bello, era conocido de muy pocos hombres (...) (Nervo, I99I, p. 24I)

Por esta razón, los animales son capaces de hacer asambleas en las que planean el dominio del mundo, presidida por Equis Robertis, un caballo, y Can Canis, un perro orador que arenga a sus compañeros al levantamiento. Muestra del discurso del segundo es el siguiente fragmento, en el que además el perro realiza una función metalingüística:

(...) El idioma surgió monosilábico, rudo, tímido, imperfecto, de nuestros labios; el pensamiento se abrió como una celeste flor en nuestras cabezas, y un día pudo decirse que había ya nuevos dioses sobre la tierra; por segunda vez en el curso de los tiempos el Creador pronunció un fiat, et homo factusfuit.

No vieron Ellos con buenos ojos este paulatino surgimiento de humanidad; mas hubieron de aceptar los hechos consumados, y no pudiendo extinguirla, optaron por utilizarla... Nuestra esclavitud continuó, pues, y ha continuado bajo otra forma: ya no se nos come, se nos trata con aparente dulzura y consideración, se nos abriga, se nos aloja, se nos llama a participar, en una palabra, de todas las ventajas de la vida social; pero el hombre continúa siendo nuestro tutor, nos mide escrupulosamente nuestros derechos... y deja para nosotros la parte más ruda y penosa 
de todas las labores de la vida. No somos libres, no somos amos, y queremos ser amos y libres... (Nervo, I99I, p 243).

En este texto se nos presenta también una distopía, entendida esta como una sociedad en la que imperan elementos que impiden la armonía entre los seres que la conforman. Hay guerras, discriminación, poder absoluto, entre otros defectos. En estos casos, “no se exige ningún rigor científico ni explicación racionalizante”. (Sánchez y Gallego, p.8).

La distopía que aparece en "La última guerra", luego de la llamada Revolución social, tiene dos etapas, la primera de ellas es la división de clases que se marca entre los humanos y los animales que han desarrollado su inteligencia y a la clase explotada:

(...) los seres vivientes estaban divididos entonces en dos únicas porciones: los hombres, la clase superior, la élite, como si dijéramos del planeta, iguales todos en derechos y casi, casi en intelectualidad, y los animales, humanidad inferior que iba progresando muy lentamente a través de los milenarios, pero que se encontraba en aquel entonces, por lo que ve a los mamíferos, sobre todo, en ciertas condiciones de perfectibilidad relativa muy apreciables. Ahora bien: la élite, el hombre, hubiera juzgado indecoroso para su dignidad aprender cualquiera de los dialectos animales llamados inferiores.

(...) No era común tratar con ellos [con los animales], sino para darles órdenes en el idioma patricio, o sea el del hombre, que todos ellos aprendían. (Nervo, I99I, p 240)

La segunda etapa inicia con la derrota de los hombres frente a los animales. Quien narra la historia es uno de los pocos hombres que quedan en el planeta: "Humanos son ellos y piadosos serán para matarnos”, señala el narrador respecto a la nueva clase dominante, integrada por los animales.

Sánchez y Gallego mencionan, además, al respecto de la visión futurista en la ciencia ficción, que mientras "Verne exploraba las posibilidades futuras de la tecnología, otros autores lo han hecho con la sociología” (p.8). En el caso de Amado Nervo, tenemos ambas exploraciones en este relato. La sociológica, ya la hemos analizado: no obstante, la tecnológica también está presente. Se menciona nueva tecnología, como los "aereociclos", "expresos magnéticos", "directísimos transétereolunares", además del "fonotelerradiógrafo", aparato con el que el narrador escribe la historia. El escritor utiliza la herramienta literaria de la narración en forma de una nota explicativa para reforzar la verisimilitud de su historia, en la cual describe la función de la máquina: "Las vibraciones del cerebro, al pensar se comunicaban directamente a un registrador especial, que a su vez las transmitía a su destino. Hoy se ha reformado por completo este aparato". (Nervo, I99I, p. 240) 
Como hemos visto, "El sexto sentido" tiene una propuesta basada en la ciencia y "La última guerra" muestra una visión futurista al relatarnos lo que ha pasado en milenios venideros de la era humana. Con ello, Nervo se separa de la “tradición” del género en el país. Estos dos cuentos son, pues, claros ejemplos de la ciencia ficción que cumplen con las características señaladas del género en obras de distintas partes del mundo, que surgen como pioneros en México y resaltan por sus temas e influencias en la literatura universal.

La noción de cambio que Isaac Asimov menciona en su ensayo como rasgo del género $\mathrm{CF}$ es uno de los temas que se desprenden en ambos relatos. Si bien tanto en "El sexto sentido" como en "La última guerra" se localizan de manera textual los señalamientos de cambios en la ciencia y en la tecnología, también existe el cambio social. En el primer relato, se detecta un guiño de la transformación de la actitud del sujeto del siglo XX hacia un individuo gobernado por el tedio, un mal que sobresale en el protagonista, como lo señala Fortino Corral (p 28I). En "La última guerra” el cambio social es más evidente, se muestra la transformación de la humanidad, que ha pasado de un sistema de explotación sobre las clases obreras (primero entre los mismos humanos y después sobre los animales) a convertirse en la especie sometida, forma ahora parte de una sociedad en la que cada humano es igual entre sí y pertenece a una gran masa que es explotada. Se manifiesta así el espíritu decadente que recorría la época del autor.

Las letras de Amado Nervo deben reconocerse como un baluarte para la ciencia ficción mexicana. Además de ser considerado como el primer autor del país que cuenta con una producción tan amplia como para reunir una antología de ciencia ficción, expuso su estudio sobre el género en el ensayo "La literatura maravillosa", y con la conferencia "La literatura lunar y la habitabilidad de los satélites que fue leída por Nervo en la Sociedad Astronómica de México en r9O4. (Miguel Ángel Fernández, 20I3)5. Con estas acciones, queda manifestada la pasión del autor por el cultivo y análisis del género ciencia ficción.

\footnotetext{
5 Se trata de un documento en línea. Fernández, Miguel. (20I3). "Breve historia de la Ciencia Ficción mexicana". En Ciencia Ficción mexicana. Consultado el 8 de junio de 2017 desde http:// cfm.mx/?cve= II:O5
} 


\section{Bibliografía}

-Asimov, I. (20I5). Sobre la ciencia ficción. Editorial FleCos. e Pub base ri.2.

- Bermúdez, M. (20I3). “Decadentismo literario”. En Semanario universidad. Universidad de Costa Rica. Consultado el 9 de enero de 2019 desde

https://semanariouniversidad.com/suplementos/loslibros/decadentismo-literario/

- Carballo, E. (I99I). Historia de las letras mexicanas en siglo XIX. Guadalajara: Universidad de Guadalajara.

- Corral, F. (2OII). Senderos ocultos de la literatura mexicana. La narrativa fantástica del siglo XIX. Madrid: Editorial Pliegos.

•Durán, M. (2008). “Prólogo”. En Cuentos y crónicas de Amado Nervo. México: UNAM.

- Fernández, B. (Antologador). (20IO). Los viajeros: 25 años de ciencia ficción mexicana. México: Ediciones SM.

- Fernández, M. (2004). "Hacia una vindicación de la ciencia ficción mexicana”. En La ciencia ficción en México (hasta el año 2002). Gonzalo Martré. Instituto Politécnico Nacional.

- Fernández, M. (2013). "Panorama de la Ciencia Ficción mexicana”. En Ciencia Ficción mexicana. Consultado el 8 de junio de $20 \mathrm{O} 7$ desde http://cfm.mx/?cve= $=$ II:26

- Fernández, M. (20I3). “Breve historia de la Ciencia Ficción mexicana”. En Ciencia Ficción mexicana. Consultado el 8 de junio de 2017 desde http://cfm.mx/?cve=Ir:05

- González, C. (2012). (18ª edición). Historia de la literatura mexicana. Desde sus orígenes hasta nuestros días. México: Porrúa.

- Herrero, J. (2000). Estética y pragmática del relato fantástico (Las estrategias narrativas y la cooperación interpretativa del lector). Cuenca: Ediciones de la Universidad de Castilla-La Mancha.

- Jameson, F. (2009). Arqueologías del futuro: el deseo llamado utopía y otras aproximaciones de ciencia ficción. Madrid: Ediciones Akal.

- Keller, E. (1991). “Distopía: Otro final de la utopía”. Reis, (55), 7-23. Consultado el io de septiembre de 2018 desde https://www.jstor.org/stable/40I83538?newaccount=true\&re ad-now=I\&seq=I\&googleloggedin=true/subjects\#metadata_info_tab_contents. 
- López, L. (2009). Formación y desarrollo del cuento fantástico hispanoamericano en el siglo XIX. Tesis doctoral. Madrid: Universidad Autónoma de Madrid.

- Martínez, J. (2OIO). “Fantasías irónicas e ironías fantásticas : sobre Amado Nervo y el lenguaje modernista”. En Biblioteca Cervantes Virtual. Consultado el 7 de enero de 2019 desde http://www.cervantesvirtual.com/nd/ark:/5985地mcpc3j7

- Moreno, F. (2008). "La ficción prospectiva: propuesta para una delimitación del género de la ciencia ficción”. En Ensayos sobre ciencia ficción y literatura fantástica. Madrid: Asociación Cultural Xatafiy Universidad Carlos III de Madrid. Páginas: 65-93

- Nervo, A. (I99I). “El sexto sentido”. En Obras completas. Tomo I. México: Aguilar. Páginas: $360-37$ I.

- Nervo, A. (I99I). "La última guerra”. En Obras completas. Tomo I. México: Aguilar. Páginas: $239^{-2} 45$.

- Ruiz, B. (20I6). "Los ensayos de Amado Nervo". En Tiempo en la casa. Suplemento de la revista Casa del tiempo. Números 30-3I. Julio-Agosto $20 \mathrm{O} 6$.

- Pascal, H. (20I3). "La Maquinaria Lúdica de Amado Nervo". En Ciencia Ficción mexicana. Consultado el 5 de junio de $20 I 7$ desde http://cfm.mx/?cve=II:27

- Sánchez, G. y Gallego, E. (Sin fecha). ¿Qué es la Ciencia-Ficción? Universidad de Almería. Consultado el 6 de junio de 20I7 desde https://w3.ual.es/ egallego/textos/que_cf.pdf.

- Schaffler, F. (Comp.) (I99I). Más allá de lo imaginado II, una antología de ciencia ficción mexicana. México: Fondo editorial Tierra Adentro. 